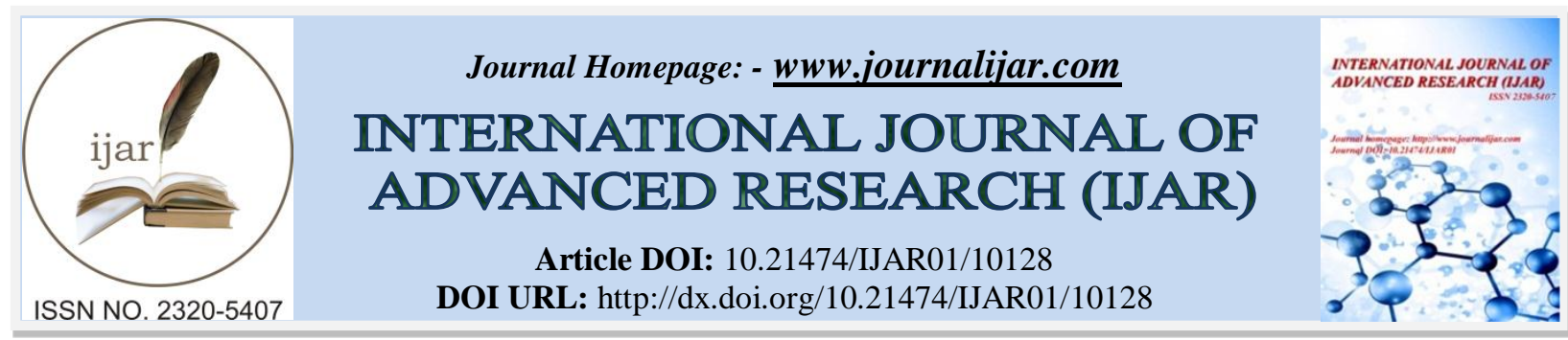

RESEARCH ARTICLE

\title{
EPIDEMIOLOGICAL AND PATHOLOGICAL PROFILE OF SKIN ADNEXAL TUMORS: STUDY OF 97 CASES.
}

Maria Dref ${ }^{1}$, Imane Boujguenna ${ }^{1}$, Anass Fakhri ${ }^{1}$, Said Amal ${ }^{2}$ and Hanane Rais ${ }^{1}$.

1. Department of anatomy and pathology, FMPM-UCAM CHU Mohammed VI, Marrakech-Morocco.

2. Department of Dermatology, FMPM-UCAM-CHU Mohammed, VI-Marrakech-Morocco.

\section{Manuscript Info}

\section{Manuscript History}

Received: 01 October 2019

Final Accepted: 03 November 2019

Published: December 2019

Key words:-

Skin Adnexal Tumors, Epidemiology.

\section{Abstract}

The Adnexal skin tumor is one of the most uncommon types of tumors. It could display multiple differentiation such as follicular, eccrine, apocrine, sebaceous and sometimes mixed differentiation; generating a mistaken diagnosis.

The world health organization differentiated in 2018, adnexal skin tumor to 2 major subtypes: 21 benign and 15 malignant.

A fourteen year retrospective case study was carried in the anatomyPathology Laboratory of the University Hospital Mohammed VI in Marrakesh-Morocco; from January 2004 to September 2019. This study aimed to describe the epidemiological and pathological profiles of skin adnexal tumors.

Among 97 patients admitted for consultation with a skin mass in different locations, 97 of them were diagnosed with skin adnexal tumors.

The epidemiological results displayed a sex ratio of 1.15 with a male predominance 52 cases $(53.6 \%)$ and 45 cases $(46.4 \%)$ for women.

The anatomy -pathology analysis showed that benign tumors represented 93 of the cases $(95.9 \%)$ while malignant tumors represented only 4 cases $(4.1 \%)$ : two cases of porocarcinoma and two of sweat gland carcinoma. Tumor differentiation was follicular in 50 cases $(51.6 \%)$, eccrine / apocrine in 44 cases $(45.3 \%)$ and sebaceous in 3 cases $(3.1 \%)$.

Copy Right, IJAR, 2019,. All rights reserved.

\section{Introduction:-}

The Adnexal skin tumors are abnormal and consist of many types. The world health organization divided these types of tumors to 21 subtypes benign and 15 subtypes malignant tumors $[1,2]$. They can be presented in different varieties such as follicular, eccrine, apocrine, sebaceous and sometimes mixed differentiation, making the diagnostic difficult $[1,5]$.

The diagnosis is essentially based on the anatomo-pathological study since the clinical aspect is not specific and sometimes misleading $[1,2,8]$. The most common tumor are benign, when malignant tumors are rare but aggressive with a poor prognosis $[1,2]$.

Corresponding Author:-Maria Dref. Address:-Department of anatomy and pathology, FMPM-UCAM CHU Mohammed VI, MarrakeshMorocco. 
Our work objective is to describe the epidemiological and pathological profiles of different type's skin adnexal tumors.

\section{Material and Methods:-}

This retrospective study was conducted in the Anatomy Pathology Unit of the MOHAMMED VI University hospital of MARRAKECH from January 2004 to September 2019. A total of 97 cases of skin adnexal tumors were diagnosed.

Our study included all patients with skin adnexal tumor, diagnosed first clinically and confirmed after by pathological study on specimen or biopsy, the validation were based on the histological classification of adnexal tumors proposed by the World Health Organization WHO (2018). Suspected and unconfirmed cases, were excluded (hamartomas and adnexal cysts).

From the anatomo-pathological data document, we collected epidemiological data: age, sex, location, size and histological type of the tumor.

\section{Results:-}

The main reason for consultation was skin mass in different locations (Table 1) (Figure 2).The average age of patients were 34 years with extreme ages ranging including ages from 19 to 87 years old. The distribution of patients through sex showed a male predominance with $53.6 \%$ for women $46.4 \%$ and the sex ratio was defined with 1.15 (Figure 1).

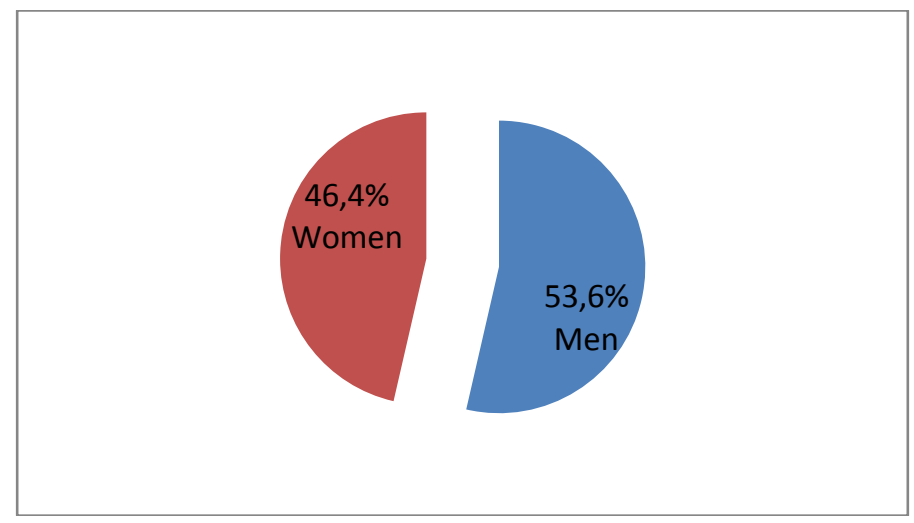

Figure 1:- Distribution of cases by gender

Table 1:- Distribution of Cases by Location

\begin{tabular}{|l|l|}
\hline Location & Percentage \% \\
\hline Head and neck & 74.3 \\
\hline Senior members & 11.3 \\
\hline Trunk & 10.3 \\
\hline Lower limbs & 4.1 \\
\hline
\end{tabular}

Benign tumors represented 93 cases (95.9\%) when malignant tumors represented only 4 of the cases (4.1\%) distributed as 2 cases of porocarcinoma and 2 cases of sweat carcinoma (Figure 2).

Different types of tumor were identified: follicular in 50 cases (51.6\%), eccrine / apocrine in 44 cases (45.3\%) and sebaceous in 3 cases (3.1\%) (Figure 3 ).

Among follicular tumors, the predominant histological type was pilomatricoma found in 23 cases (23.7\%) followed by trichoadenoma and trichoblastoma in 10 cases for each (9.7\%). Among eccrine / apocrine tumors, there were 21 cases $(21.7 \%)$ of hidradenoma, 11 cases (11.3\%) of eccrineporoma (figures 4,5,6 et 7 ).

For the sebaceous tumors, only 3 cases of sebaceous adenoma were defined (Table 2). 


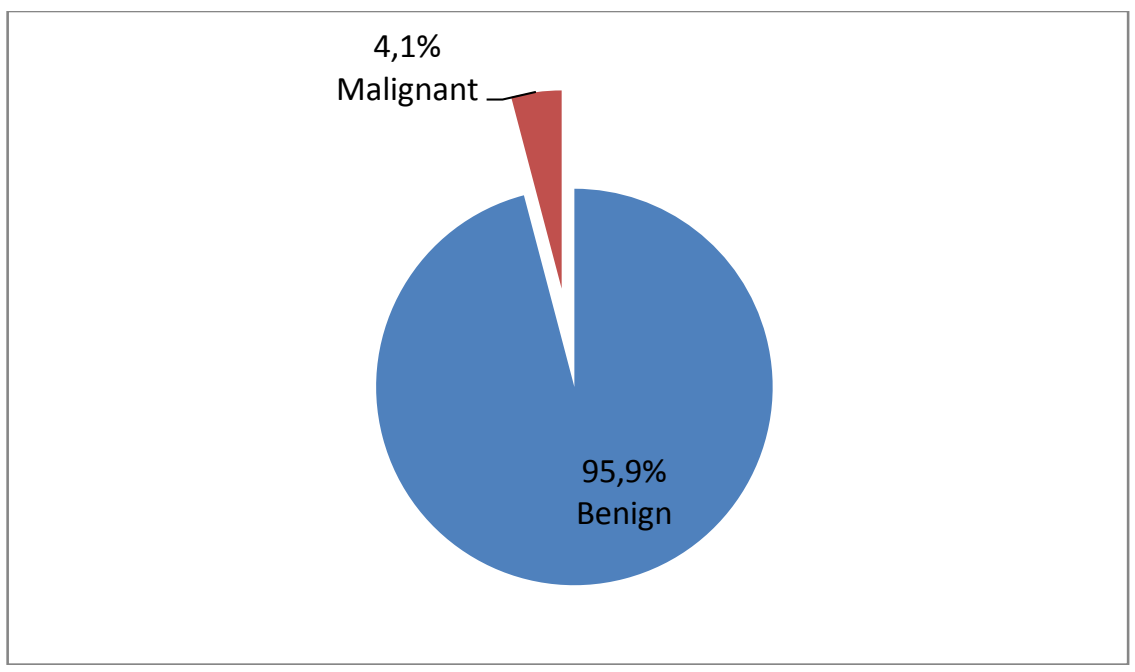

Figure 2:- Distribution according to malignancy

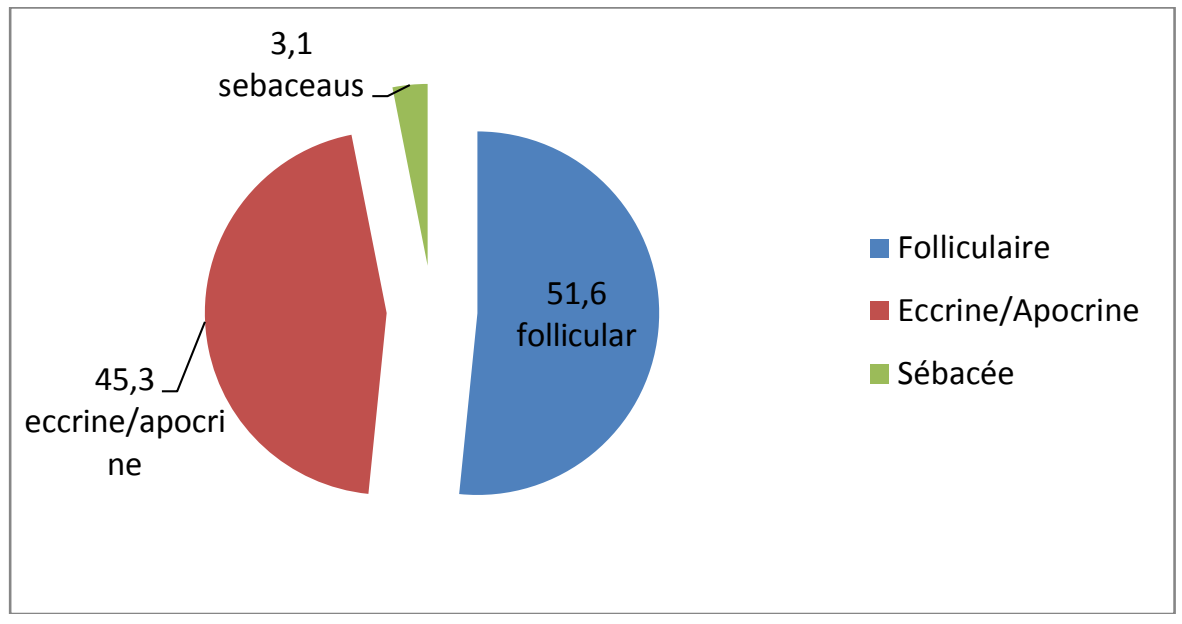

Figure 3:- Distribution according to differentiation

Table 2:- Distribution according to differentiation and histological type

\begin{tabular}{|l|l|l|}
\hline Tumor differentiation & Histological type & Percentage \\
\hline \multirow{4}{*}{ Follicular } & Pilomatricoma & $23,7 \%$ \\
\cline { 2 - 3 } & Trichoadénoma & $9.7 \%$ \\
\cline { 2 - 3 } & Other & $18,2 \%$ \\
\hline \multirow{2}{*}{$\begin{array}{l}\text { Eccrine/ } \\
\text { apocrine }\end{array}$} & Hydradenoma & $21,7 \%$ \\
\cline { 2 - 3 } & Porome & $11,3 \%$ \\
\cline { 2 - 3 } & Papilliferums syringocystadoma & $5,1 \%$ \\
\cline { 2 - 3 } & Porocarcinoma & $2,1 \%$ \\
\cline { 2 - 3 } & Other & $5,1 \%$ \\
\hline Sebaceous & Sebaceous adenoma & $3,1 \%$ \\
\hline
\end{tabular}




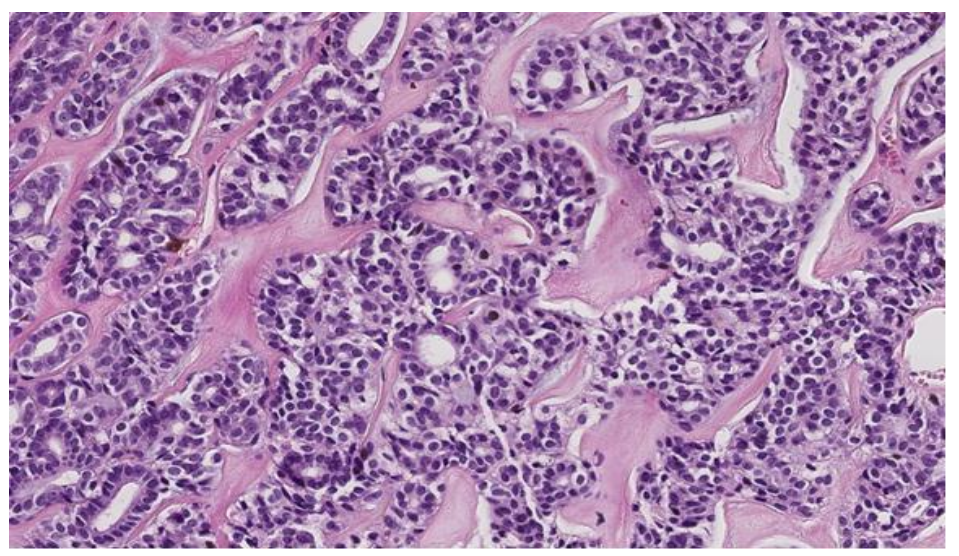

Figure 4:- Histological image of Chondroid syringoma [Iconography of the pathological anatomy department CHU Mohammed VI Marrakech]

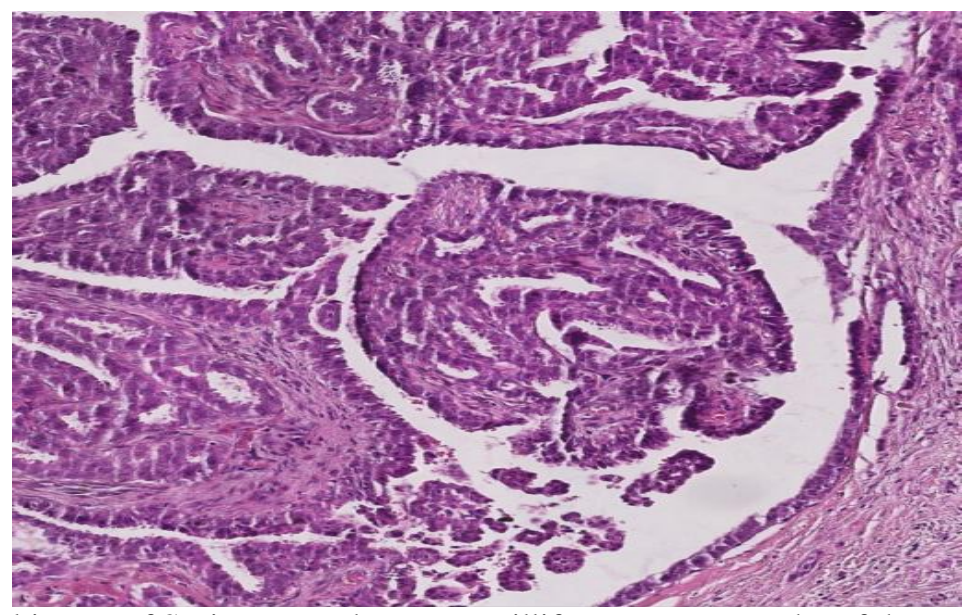

Figure 5:- Histological image of Syringocystadenoma papilliferum [Iconography of the pathological anatomy department - CHU Mohammed VI Marrakech]

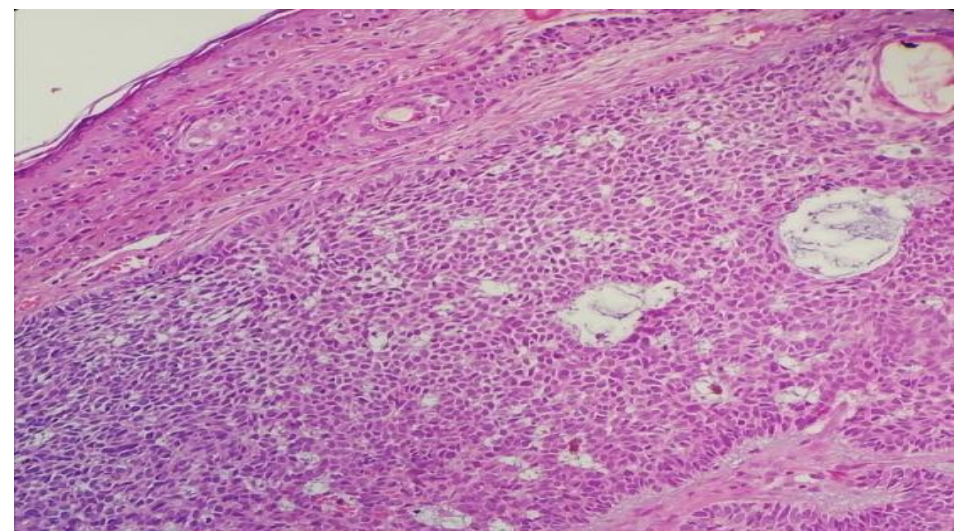

Figure 6:- Histological image of Trichoblastoma [Iconography of the pathological anatomy department - CHU Mohammed VI Marrakech] 


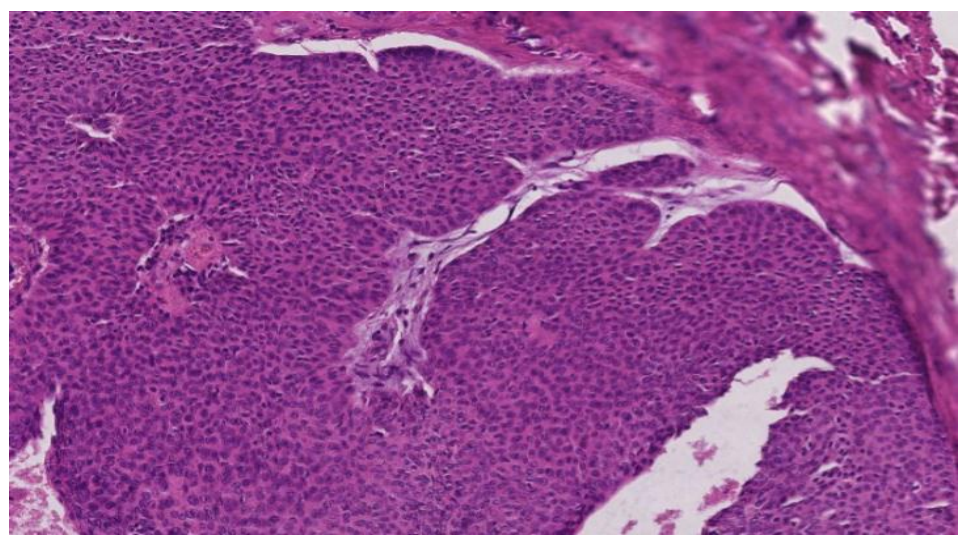

Figure 7:- Histological image of Hidroadenoma [Iconography of the pathological anatomy department - CHU Mohammed VI Marrakech]

\section{Discussion:-}

Few studies have focused on Skin adnexal tumors, due its complexity [3]. The average age of our patients was 34 years old; this result is comparable to that reported by Gayathri et al that show the average age was $35.2 \%$ and Samaila et al. with an average age with 33 years old. [9, 10], considering the sex factor there was a slight male predominance (sex ratio of 1.15 ), which is consistent with the literature $[1,5,8]$.

In our case study, adnexal skin tumors are mainly located in the region of the head and neck, while the limbs and trunk are less affected; this is due to the great abundance of cutaneous adnexal structures at this level, this result is explained by Sharma et al. [5], proved that cutaneous adnexal tumors affect the head and neck region in $64.28 \%$ of cases, the trunk in $14.28 \%$ of cases, and the upper limbs in $12.5 \%$ of cases. This is also authentic with the study of Nair and al [6].

Benign tumors are the most common, it is in agreement with all other statistics in the literature $[1 ; 5,6,8,10]$. Malignant tumors remain rare and occur at a later age $[6,8]$. For Nair and Ankit et al., Eccrine / apocrine tumors are the most common followed by follicular and sebaceous tumors $[5,6]$.

In this study, follicular differentiation is slightly more frequent (51.6\%). followed by eccrine / apocrine tumors $(45.3 \%)$ and sebaceous tumors (4.2\%). Pilomatrixoma is the most common histological type in our series (23.7) followed by hidradenoma (21.7), which is consistent with literature $[5,6,8]$. The other histological subtypes are rarer $[5,6,7,8$,$] .$

\section{Conclusion:-}

This work made it possible to study skin adnexal tumors, which is only studied in few cases The adnexal skin tumors are most often benign but characterized by their clinical polymorphism, which explains the importance of clinical and histological data that confirm or deny clinical diagnosis.

\section{Bibliography:-}

1. El ochi,m r. , boudhas,a., allaoui, m. ,rharrassi, i. , chahdi, h., al bouzidi,a. Et m.oukabli (2015). Les tumeurs annexielles cutanées : les tumeurs annexielles cutanées: étude anatomopathologique à propos de 96 cas. The Pan AfricanMedical Journal.2015.20.389.6202

2. Elder,d., elinistas, r., bd ragsdale, bd. (1997). Levers histopathology of the skin 8 thed: tumours of the epidermalappendages. In: Elder D, Elinistas R, Jaworsky C, Johnson B Jr, editors. 8 th ed. Philadelphia: Lippincott Williams and Wilkins; 1997. pp. 747-803.

3. Obaidat, na., , alsaad, ko., ghazarian, d. (2007). Skin adnexalneoplasm-part 2: An approach to tumours of cutaneoussweatglands. J Clin Pathol. 2007;60 (2):145-59.

4. Kamyab-hesari, k., balighi, k., afshar, n., aghazadeh, n. , rahbar,z. Seraj ,m. (2013) clinicopathologicalstudy of 1016 consecutiveadnexal skin tumors. Acta med iran. 2013;51 (12):879-85.

5. Radhika, k., phaneendra, bv., rukmangadha, n. , reddy,mk . (2013) a study of biopsyconfirmed skin adnexaltumours: experienceat a tertiary care teachinghospital. J Clin SciRes. 2013;2(1):132-8. 
6. Pujani, m., madaan, gb., jairajpuri, zs., jetley, s., hassan, mj., khan,s. (2016). Adnexal Tumors of Skin: An Experience at a Tertiary Care Center at Delhi Ann Med Health Sci Res. 2016 Sep-Oct; 6(5): 280-285

7. Nair, ps. (2008). A clinicopathologicstudy of skin appendagealtumors. Indian $\mathrm{j}$ dermatolvenereolleprol. 2008;74(5):550-554.

8. Saha, a., das, nk., gharami, rc. , chowdhury, sn., datta, pk. (2011). A clinico-histopathological study of appendageal skin tumors, affectinghead and neck region in patients attending the dermatologyopd of a tertiary care centre in easternIndia. Indian Journal of Dermatology. 2011;56 (1).

9. Rajalakshmi, v., selvakumar, s., rajeswari, k., meenakshisundaram, k., veena , g. (2014). Case series of skin adnexaltumours. J Clin DiagnRes. 2014;8(9):07-10.

10. Samaila, m., (2008) adnexal skin tumors in zaria, nigeria. Ann Afr Med. 2008;7(1):6-10. 